


\title{
Santidad, kratofanía y depuración: la narrativa corta de Jesús Gardea
}

\section{Holiness, kratophany and depuration: the short narrative by Jesús Gardea}

\author{
Daniel Samperio Jiménez \\ Universidad Autónoma Metropolitana-Azcapotzalco, México \\ dasj@azc.uam.mx
}

Resumen: Además de hacerlo con una considerable cantidad de novelas, Jesús Gardea desarrolló otra porción importante de su mundo ficcional en seis libros de cuentos. Este artículo propoxne un recorrido por los cuentos más significativos de Gardea de acuerdo con el proceso de depuración experimentado por su lenguaje y manera de narrar, así como con la mayor presencia de ciertas kratofanías en las historias. Para ello no se deja de considerar la concepción de escritura del autor, así como determinados fenómenos de su narrativa como los delirios y ensueños, o bien los llamados "espantos" y "trastornados" que configuran aspectos esenciales de su mundo ficcional.

Palabras clave: Jesús Gardea, cuento, escritura, kratofanía, negatividad.

Abstract: In addition to doing so with a considerable number of novels, Jesús Gardea developed another important portion of his fictional world in six storybooks. This article proposes a journey through the most significant stories of Gardea according to the purification process experienced by their language and way of narrating, as well as the greater presence of certain kratophanies in the stories. To do this, the author's 
conception of writing is considered, as well as certain phenomena of his narrative such as delusions and daydreams, or the so-called "espantos" and "trastornados" that make up essential aspects of his fictional world.

Keywords: Jesús Gardea, Story, Writing, Kratophany, Negativity.

Recibido: 20 de enero de $202 \mathrm{I}$

Aceptado: 22 de abril de $202 \mathrm{I}$ https://dx.doi.org/Io.I 5 I 74/rv.vi3i28.596

Gl tercer capítulo de De Kafka a Kafka, de Maurice Blanchot, Ecomienza con una reflexión acerca del compromiso y aun la obsesión del autor con la literatura, que para muchos de sus lectores y exégetas suele entenderse mejor "si se reconoce en la literatura el medio que él escogió para cumplir su destino espiritual y religioso" (Blanchot, 1991: 98). Mucho se ha comentado al respecto, en especial en relación con el carácter negativo que adquieren elementos del mesianismo judío en su obra (Löwy, 2018: 79). Por su gesto de abrazar de tal manera la literatura que lleva a considerar fenómenos que la rebasan, es inevitable pensar en el caso de Kafka a propósito de una ética y una estética de lo sagrado. Cuando Max Brod afirmaba que habría que situar su vida y su obra en la categoría de santidad y no en la de literatura, o Pierre Klossowski señalaba que, además de crear una obra, Kafka también tuvo que entregar un mensaje (Blanchot, 1991: 98), apuntaban a reconocer que la escritura fue para él menos una cuestión de estética que de salvación: la obediencia a ese mensaje que sostuvo su vida entera.

En pocos casos de la literatura mexicana se puede advertir un posicionamiento parecido al de la obra de Jesús Gardea. Sus cuentos y novelas constituyen uno de los mundos más enigmáticos, 
complejos y fascinantes de la narrativa escrita en México a finales del siglo xx. Aunque dejó pocas reflexiones sobre su propia escritura, es posible formarse una idea de cómo concebía su labor. En varias entrevistas y el breve texto "La palabra es el cuento" (Gardea, 2008), el autor señalaba una dimensión que trascendía la literatura. En más de una ocasión, llegó a referirse a su trabajo en los siguientes términos:

Pienso que la literatura, cuando es auténtica, tiene una dimensión moral, tanto para la persona que hace la literatura como para el lector que va a ella. Por eso digo que si realmente uno está siendo auténtico al escribir no puede menos que irse convirtiendo, y creo que esa conversión tendería a una especie de santidad. O sea que no puedes escribir impunemente sin convertirte en un chamuco o en un santo. Yo prefiero creer que en un santo (Gardea, 1993b: 67).

Incluso, sostenía la existencia de relaciones entre la santidad y el lenguaje acudiendo a la neurología y a la teología:

El lenguaje es producto de una estructura moderna del cerebro que es la corteza. Lavar los trastes, hacer el amor o hacer una mesa depende de estructuras medias, del hipotálamo, o también del cerebelo, que es el que coordina los movimientos físicos. En cambio, la corteza, que posibilita hablar, escribir, hacer un lenguaje, es neurológicamente la última etapa de un desarrollo que tiene unos quinientos millones o mil millones de años, en los océanos o en los mares de ese entonces, desde el momento en que se inicia con los cordados lo que va a ser andando el tiempo el cerebro. Luego, si es la última etapa, ¿por qué pensar que esta evolución del sistema nervioso central terminará en la corteza, por qué no pensar que vendrá una estructura más arriba de ella? Pero ya no una estructura de carácter físico sino de carácter metafísico, que es 
donde iría a dar la creación de un lenguaje. Quiero creer que iría a dar a una dimensión moral, donde viven los ángeles, los santos, o lo que posibilita que un hombre se haga santo o angélico (Gardea, 1993a: 69).

Entre otros aspectos de su trabajo literario, Gardea solía insistir en el sometimiento a una fuente, así como, en el mismo tono, a un trabajo lento y aproximativo con las palabras. Por ello es significativo cómo, en la medida en que percibía eso que trascendería a la literatura, ponía mayor atención a esta. Ello se advierte en ciertos aspectos casi técnicos y de trabajo casi artesanal con el lenguaje, como desde luego también en el trabajo artístico, de un estilista y buscador de imágenes. Dados estos elementos, habría que decir que la escritura de Gardea guarda correspondencias con cierto lenguaje aproximativo de la mística y la ascética: depuración, silenciamiento, alusión, secreto, elipsis, retención, negatividad. Ese tratamiento del lenguaje a lo largo de la obra de Gardea se manifiesta especialmente en los cuentos. De modo más visible a como ocurre en sus novelas, tanto el lenguaje como la forma de narrar van reduciéndose en cada libro de cuentos. Se trata de un fenómeno que evidentemente encierra un elaborado proceso de condensación. De manera similar a María Zambrano, hay en Gardea una retención y un recogimiento desde los que se formula la escritura (Zambrano, 1987: 31-38). Sin embargo, su narrativa pareciera que no trata de descubrir ningún secreto, sino de comunicar la imposibilidad de conseguirlo.

El llano representa el espacio fundacional de la ficción de Gardea. No se trata solamente de un territorio hostil y casi perdido en la nada, sino abierto a recónditas dimensiones conforme la narrati- 
va de Gardea lo explora. Las reverberaciones del sol, la densidad de las sombras, la consistencia del viento, la crudeza del invierno, las tolvaneras de marzo, y hasta los cantos de grillos y chicharras describen un mundo vivo y complejo. Por eso no es casual que, a veces, estos elementos adquieran tal fuerza que susciten ensueños y presencias sobrenaturales. Hay una suerte de resonancia del cosmos y la naturaleza en determinadas "apariciones". Con ello se convocan delirios, voces y aun fantasmas. Los primeros constituyen tanto una tregua como un consuelo ante la hostilidad del llano. Las segundas tienen una participación fundamental a lo ancho del universo narrativo de Gardea. Desde luego, hay una honda filiación con el mundo de Rulfo. En parte, para Gardea también vendrían a ser las voces de los muertos. Al menos, es el planteamiento que subyace en un cuento clave del primer libro: "Hombre solo" (Los viernes de Lautaro, 1979). ${ }^{1}$ Sin embargo, conforme el autor sigue indagando en su mundo, ese sentido de las voces deja de ser el mismo. También alude a ciertos agentes maléficos que no pertenecen a la realidad en que se desenvuelven los personajes, ya que no son los muertos sino otro tipo de presencias. Lo mismo llega a suceder con ciertos fantasmas - para referirse a ellos con un término tradicional, pues en el mundo ficcional de Gardea se reconocen más bien como "espantos"-

Se podría decir que este tipo de delirios, voces y "espantos" constituyen la creación más lograda y la quintaesencia del llano, en tanto representan presencias extravagantes, por llamarlas de algún modo, pues justo están en la linde de lo vivo y lo inerte, de lo mundano y lo trasmundano. Se trata de apariciones varadas o

${ }^{1}$ En adelante todos los textos incluidos en Reunión de cuentos (1999b): Los viernes de Lautaro (1979), Septiembre y los otros días (1980), De Alba sombría (1985), Las luces del mundo (1986) y Dificil de atrapar (1995), se indicarán con la fecha de su publicación original; sin embargo, como se indica, las citas son de la edición de 1999. 
deambulantes en medio de la extensión del llano. Cabe señalar que las "afueras" de poblados incipientes retratados en sus historias, y sus espacios desiertos y hostiles, se vuelven propicios a la manifestación de esta clase de ensońaciones, alucinaciones y aun espejismos. En el fondo de relatos como "Hombre solo", "Los viernes de Lautaro", "Más frío que el viento", "Arriba del agua", "La guitarra", "Las luces del mundo", "Livia y los sueños", permea esta visión decantada.

Especialmente, "Arriba del agua" (De Alba sombría, 1985) condensa esa dimensión hostil del espacio que fomenta el delirio: "El ruido se mueve, se aproxima. Las piedras revientan de sol. La sequía no va a dejarnos nada; ni el juicio siquiera. Dicen que en el llano andan almas resucitadas de animales. Que llevan en orden sus huesos pisando firmes la tierra. Tantos años sin agua dan para todo. Espantos y fantasmas" (Gardea, 1999b: 311). Se relata una escena enigmática donde una muchacha con lentes negros llega imprevistamente al caserío de un hombre. La visita resulta tan extraña como inhóspito es el llano que ha andado la muchacha. Sin embargo, el narrador se lo explica a partir de cierta creencia extendida que supone que la sequía del llano aturde y pierde a algunas personas: "Algunos trastornados regresan a sus casas, de mano de sus familiares; otros, la mayoría, se meten al llano, nadie los vuelve a ver" (313). El narrador por ello se compadece de la muchacha: "Ojalá y cuando ella se vaya la encuentren sus parientes. No es para las soledades del llano" (313).

En este cuento, se perfila lo que en el mundo ficcional de Gardea sería un "espanto" y un "trastornado". La muchacha vendría a ser una trastornada que deambula por el llano. Empero, a lo largo del relato hay algunos rasgos de la muchacha que llevan la lectura hacia otra dirección. Por ejemplo, sus lentes negros interponen una barrera que impide al hombre mirarla directamente a los ojos, así como en algún momento profiere una queja que hace dudar 
sobre su verdadera identidad: "He caminado. Como los animales que penan por el llano” (Gardea, 1999b: 311). No se sabe de dónde viene o quién es realmente la muchacha, si acaso proviene del mundo animal o es una invención del llano. ${ }^{2}$

Conforme avanza la historia, se va reconociendo al narrador también como un "trastornado". Este sueña con un río en medio de la sequía atroz, además de que supuestamente lo hace por un "encargo" que jamás se explica. El rumor del río, con tules y juncos meciéndose, remolinos, caracoles, así como sus reflejos, casi lo ensordecen y deslumbran. Es como si el hombre hubiera perdido contacto con la realidad, pero la aparición de la muchacha lo trae de vuelta a la sequía, pues descubre que ella es como ese río en mitad del llano.

Hacia el desenlace, pareciera que la muchacha se termina revelando como un "espanto" justamente. A los indicios anteriores en relación con los lentes oscuros y la queja, se suma la transfiguración de su presencia, que inspira tanto desconfianza como fascinación en el narrador. Pero, alternativamente, tampoco deja de aparecer como una "trastornada":

— Me tenían guardada. Hasta el día de hoy. Me dijeron: Jimena, vete al llano, necesitas el aire. Me arreglé los olanes. Me puse los lentes. Después, el botecito. Pero ya en el llano, tuve miedo. De los mezquites salían fantasmas muertos de sed.

-Eso cuentan, Jimena, que hay fantasmas allá.

La muchacha levanta una mano y extiende los dedos.

\footnotetext{
${ }^{2}$ Un par de apariciones fascinantes de "espantos" y "trastornados" que merecen especial mención, en la narrativa de Gardea, tienen lugar en "La guitarra" y "Las luces del mundo", como almas deambulantes que buscan lo vivo y no se sabe de dónde vienen. Aparecen fortuitamente, casi conforme sopla el viento o hay variaciones de luz, y del mismo modo se esfuman.
} 
-Cinco. Todos tenían cuernos. Ninguno como los del venado que hay en el calendario de mi cuarto.

La mano me deslumbra; su forma es perfecta; irradia, como una aparición. La imagino acariciando, envolviendo... Es un terciopelo profundo.

- Jimena, no me gustan tus lentes.

La mano baja; se desmorona el gesto.

-No sé si me estás mirando. No sé si de verdad sentiste el miedo o el agradecimiento que dices (Gardea, 1999b: 314).

La ambigua identidad de la muchacha constituye el punto final del cuento, cuando la compasión que inspira se convierte en una sensación amenazadora pero también cautivante. A tal punto que el narrador no la rehúye sino que, como se sugiere, es atrapado por el delirio real que representa: "La muchacha se acerca. Vuelvo a sońar con el río, con los caracolitos y la frescura. Los olanes de la blusa ceden al ímpetu de la corriente; se abren como las alas de una paloma volando arriba del agua, de las frutas" (Gardea, 1999b: 314).

En este mundo de misterio, se advierten indicios de una realidad compleja y latente, la cual lleva a replantear qué se narra. No está muy claro el plano existencial de los personajes entre imágenes, delirios y ensueños. Habría remanentes de una cosmovisión mágica que anima el fondo de la historia mediante una fuerte voluntad de simbolización. A lo largo del mundo ficcional de Gardea, hay que destacar cómo el sol, la lluvia, el viento, el polvo, la nieve, las sombras, el calor, el frío, incluso los insectos, adquieren cierto protagonismo y actúan poderosamente en las historias. La manifestación de esas sensaciones comunica el sentimiento de las cosas animadas. En una narrativa tan entregada a los elementos, este tipo de fuerzas se vuelven determinantes. El llano, en este sentido, constituye un cosmos en plenitud a pesar de su aparente esterilidad y desamparo. Por lo mismo, se lo experimenta como "un 
organismo real, vivo y sagrado" que "descubre a la vez las modalidades del Ser y de la sacralidad" (Eliade, 1973: 102). La sacralidad de la naturaleza estaría presente en ese tipo de hierofanías cósmicas y biológicas que recoge la escritura.

Sin embargo, el "espanto" en especial se entendería más bien en el orden de las kratofanías en tanto manifestaciones de fuerza que son temidas y veneradas (Eliade, 1972: 38). ${ }^{3}$ Los lentes oscuros de la muchacha suponen el primer indicio de ello, pues impiden que sea mirada directamente quien está “'maculado', y por consiguiente 'consagrado", distinto, "en cuanto régimen ontológico, de todo lo que pertenece a la esfera profana" (Eliade, 1972: 38-39). ${ }^{4}$ El temor y, a la vez, la atracción que inspira la muchacha en el narrador tiene como trasfondo la ambivalencia de lo sagrado, en el entendido de un contagio que lo mismo repele y atrapa. ${ }^{5}$

${ }^{3}$ Como la hierofanía, Eliade introduce también el término kratofanía en el Tratado de historia de las religiones para referirse a una variedad de lo sagrado, en este caso, como una manifestación de poder cuya naturaleza se desconoce y estremece.

${ }^{4}$ En algunos otros momentos de la narrativa de Gardea, la referencia a unos lentes oscuros o a una mirada sombría se vuelve un motivo reiterado. En términos generales, sugiere una presencia demoníaca que, por lo mismo, suscita desconfianza y aun algo de miedo. Por ejemplo, en "Difícil de atrapar": "El hombre no le había dado ni un trago a la cerveza. Solamente me miraba. Los vidrios de sus lentes eran como hoyos siniestros. Se los había hecho el diablo. Sorprendía la sonrisa de burla en el hombre. Una florecilla ácida entre sus dientes" (460). $\mathrm{O}$ en $\mathrm{El}$ diablo en el ojo: "-Orive, usted y yo hemos sido, esta mañana, los verdaderos hombres. - Usted, no. Hirió a Meneses — Borja guardaba la navaja. —Un diablo — dijo. Orive le miraba, punzante, a los ojos. Pero en la hondura nada veía Orive" (41).

${ }^{5}$ Eliade explica la kratofanía en relación con la condición prohibida y consagrada del tabú. Tiende así una línea de diálogo con Freud, quien desde Tótem y tabú, así como en "Lo ominoso", comenzó a sondear la existencia de una pulsión de muerte en "Mas allá del principio del placer". Habría que reflexio- 


\section{III}

El llano contribuyó a configurar significativamente un mundo más hondo en la narrativa de Gardea. Además de esos "espantos" y "trastornados", otro elemento característico lo representan ciertos hechos gratuitos y hasta piadosos en un medio tan precario donde no cabría más que la mezquindad; por ejemplo, en cuentos como "Todos los años de nieve", "Nada se perdió", "La orilla del viento", "De Alba sombría” y "El perro". Lo contrario también se torna un aspecto determinante, en tanto el llano desata rencillas, desacatos y venganzas. Hay que decir que este tipo de relatos son los más extendidos y constantes en los libros de cuentos de Gardea. Estos encierran en germen la clase de historias que el autor desarrolló en parte considerable de sus novelas. Se reconocen algunos rasgos generales: un hombre o grupo que anda a tientas en un espacio cada vez más cerrado, y trama algo que nunca es explícito o sigue un liderazgo que ejerce tiranía, por lo que inevitablemente ocurren actos de rebeldía, traición o ajuste de cuentas; por ejemplo, en "Como el mundo", "Las traiciones", "Entre ladrones", "Acuérdense del silencio", "Los abanicos", "La cizaña", "El trono" y "La carpa”.

En este medio estrecho y frágil, la envidia, la avaricia o aun el simple orgullo rápidamente dan paso a la confrontación, aunque mantenida en un estado de latencia a veces casi insoportable. El curso y desenlace de algunas historias radica en el asedio y, a menudo, el asesinato final de uno de los personajes, como en "La acequia", "Un viajero en la Florida", "Puente de sombra" y "Difícil de atrapar". Sin embargo, el desenvolvimiento de la narración en otros relatos es más enigmático, a tal punto que este tipo de final

nar que la kratofanía plantearía, a su vez, un fondo pulsional de vida y muerte similar por ambivalente. 
resulta bastante sorpresivo. A veces esa súbita impresión se intensifica, debido a que no se narra el asedio final o el asesinato propiamente, sino su inminencia, inevitabilidad y fatalidad. El aparente desconocimiento de los motivos y el ataque ineludible son patentes en cuentos como "Trinitario", "Vámonos ya", "Pálido como el polvo", "Los amigos", "El vendedor", "Las fintas" y "Después de la lluvia”. La tensión narrativa de estos relatos no se alcanza a liberar y su desenlace produce un desconcierto en escalada que perdura más allá de la lectura. Estas historias dan cuenta de un mundo indescifrable y absurdo. En el fondo, quizá los hechos solo se explicarían por el desasosiego y la violencia que el llano pareciera inexorablemente incitar en los personajes.

Sin embargo, el llano roza dimensiones desconcertantes en historias donde sentimientos de codicia, envidia o la soberbia parece que no explican con suficiencia la agresividad imperante en ese mundo. Esta yace contenida y concentrada en el fondo de los personajes, a punto de dispararse por o sin el menor motivo. Ciertamente, el llano a veces representa una imagen precisa del infierno en que sus habitantes sobreviven en absoluto desamparo. De hecho, la sombra del diablo asoma en varios relatos, y algunos personajes vendrían a ser pobres diablos desarrapados. ${ }^{6}$ En ocasiones, surge la duda de que una efectiva instancia maligna provoque esa desorientación y ese daño. En este sentido, parece tratarse de un mundo que, una vez arrojado a la intemperie por una suerte de

${ }^{6}$ El diablo y el mal constituyen elementos decisivos en la ficción de Gardea, como ya se pudo advertir a propósito de los lentes oscuros y ciertas miradas sombrías. Cabe señalar la relación que, en las historias, guardan con un fondo agresivo pulsional, así como su manifestación en diversas formas que van desde el hedor hasta el silencio pasando por las sombras, de las cuales esta última es la más recurrente. A partir de la imagen del llano como infierno, se tocan fibras sensibles de ese mundo de desesperanza, brutal, sin mujeres, fantasmagórico. Infierno quizá gnóstico que guarda matices semejantes a los de Kafka y Rulfo. 
deus otiosus (Eliade, 1972: 64-68) o deus absconditus (Otto, 1965: 132-153), ha quedado sumido en el olvido. El desamparo en que perviven sus habitantes fácilmente deja flancos abiertos al Mal. El llano constituye así el lugar propicio no solo de delirios, voces y espectros, sino incluso de presencias esencialmente malignas, en apariencia nada humanas. Entre los hombres errarían como "espantos", o bien los hombres estarían muy cerca de serlo.

La narrativa de Gardea insiste en indagar en esa especie de kratofanías que constituyen poderes terribles en las historias. Pero no se trata solamente de los que podrían pasar por "espantos", sino de la intensa conmoción que producen en el mundo ficcional. Subyace en él un hondo escepticismo acerca de lo que se cuenta. El desconcierto posee rasgos kafkianos por la forma como parece sentenciarse desde lo insondable la fatalidad de los personajes y la dimensión de pesadilla que esto supone. Más allá de la mitología del llano, se agudiza con mayor profundidad el carácter enigmático de las historias en espacios cerrados e interiores, paradigmáticos en cierto modo de una situación de condena. En ese ámbito, la narrativa de Gardea radicaliza y depura una indagación sobre una experiencia que parece revelar lo numinoso y el "misterio tremendo" (Otto, 1965: 16-48). Se torna cada vez más delgada o francamente desaparece la línea entre lo que sucede en las historias y sus causas en cuentos como "Todos", "Los visitantes", "El cuarto", "La queja" y "El guía".

Si bien Gardea había dado muestras de indagar esa experiencia en sus primeros dos libros - "En la caliente boca de la noche", "Gemelos" y "El fuego en el árbol"-, no es sino hasta aquellos cuentos de Difícil de atrapar y Donde el gimnasta que el proceso de depuración experimentado por su escritura pone en narración un fenómeno bastante complejo y con varias pistas para una posible comprensión de su propuesta narrativa. Antes de intentar explorarlo, cabe mencionar un aspecto que atraviesa varios relatos signi- 
ficativos y que tiene relación con esa indagación de lo numinoso. En cuentos como "La pecera", "Las puertas del bosque", "Latitudes de Habacuc", "El mensajero" y "Donde el gimnasta", los protagonistas responden a un llamado y cumplen un destino, aunque eso suponga vivir marginados o incluso su aniquilación. En tanto vocación, cabría reconocer una especie de gracia por tortuosa que pueda ser la vía.

En cambio, en cuentos como "La queja" (Donde el gimnasta, 1999) sucede lo contrario pues los personajes no tienen elección $\mathrm{y}$, más que dirigirse, son alcanzados por lo inexorable. La desorientación, la fatalidad y la alucinación se vuelven mayúsculas en los términos breves y casi minimalistas que componen el relato. Desconcierta como perturba sin duda la falta de indicios en este tipo de situaciones sobrecargadas. Más allá de los personajes, el mayor estremecimiento recae en el lector. En este caso, se trata de un cuarto al atardecer, un grupo de hombres y el ruido de una queja que se cierne desde el pasillo: "Les parece que tiene algunos registros muy hondos: van más allá del aire y la luz. Un viento baja después y los nubla a todos. Cesa el viento: cada quien se busca, como extraviado, en la mirada del otro" (1999a: 57). Además de los mínimos elementos echados a andar en la historia, los blancos tipográficos que dividen breves unidades de narración intensifican todavía más la impresión aterradora de la queja. En ellas se van describiendo distintos episodios en los que esta es, progresivamente, más ruidosa y omnipresente. En uno de ellos, sin otro medio para escapar o guarecerse, los hombres idean dibujar sus volutas conforme la escuchan. En otro, intentan organizarse para indagar y vigilar el pasillo. Pero todo parece inútil ante su obstinación, como se relata en este fragmento:

La oyen quejarse otra vez. El quejido como en profundas conchas, resuena ahora en el interior de todos los cuartos. 
- Son varias las que se quejan.

- Sonó más de una.

-No. Sigue siendo una; la del principio.

-No se endereza; no sube como antes, al cielo. Sino de cuatro en cuatro. Como si se arrastrara.

—Como si viniera para acá (1999a: 57).

Con el avance del atardecer los hombres echan en falta la luz, mientras se mantienen a la expectativa de la entrada sombría del pasillo. En la última unidad, no se sabe cuánto tiempo ha pasado pues ya están a oscuras. Fuera de cualquier interpretación, el relato no hace más que presentar un motivo incesante pero sin dirección clara, trabado en el texto, más inquietante cuanto más precisado. Cuando los personajes se preguntan qué ha sido de su compañero enviado a explorar el pasillo, "se callan, y en el silencio del cuarto, sostenida, enloquecedora vuelve a sonar la queja" (1999a: 61).

\section{IV}

La narrativa corta de Gardea es paradigmática tanto en la depuración como en la aparición de lo numinoso en su escritura. Da la impresión de que, conforme se adelgaza su lenguaje narrativo, los elementos delirantes en las historias adquieren una fascinante nitidez. En principio, podría resultar desconcertante la relación sugerida entre la santidad y el lenguaje cuando su ficción tiende a una manifestación mayor de ciertas kratofanías. La experiencia de lo sagrado tiene que ver más con modos primitivos o heterodoxos mientras es menos moralizada, racional y aun "humana" esa experiencia. En términos de ese elemento extraliterario que anima la escritura, es paradójica la inspiración teológica que presupone la salvación y la gracia, en tanto la naturaleza o los elementos del mundo descritos en las historias no son ejemplares de ningún ac- 
ceso sino todo lo contrario. Este equívoco de ningún modo casual es la mejor expresión de una escritura en que se vive intensamente las contradicciones entre lo demoníaco y lo angélico. Del llano como generador de delirios vívidos y consoladores al desierto en su antigua acepción propicia a lo diabólico y el mal tanto humano como inexplicable, la escritura de Gardea ha ido sondeando por un camino de depuración y retención del lenguaje. La escritura pasa por un proceso de negatividad que termina concibiendo un mundo indiferente a la piedad o el mal. Más allá de la línea del horror, habría un vaciamiento suficientemente medido y meditado que coloca la obra de Gardea en diálogo con el zen.

\section{Bibliografía}

Blanchot, Maurice, 1991, De Kafka a Kafka, Jorge Ferreiro Santana (trad.), Fondo de Cultura Económica, México.

Eliade, Mircea, 1972, Tratado de historia de las religiones, Tomás Segovia (trad.), Era, México.

Eliade, Mircea, 1973, Lo sagrado y lo profano, Luis Gil (trad.), Guadarrama, Madrid.

Freud, Sigmund, 1986, Tótem y tabú [1913], Obras completas, t. 13, José L. Etcheverry (trad.), Amorrortu, Buenos Aires, pp. 1-162. , 1992a, "Lo ominoso" [1919], Obras completas, t. 17, José L. Etcheverry (trad.), Amorrortu, Buenos Aires, pp. 215-251.

, 1992b, "Más allá del principio del placer" [1920], Obras completas, t. 18, José L. Etcheverry (trad.), Amorrortu, Buenos Aires, pp. 1-62.

Gardea, Jesús, 1993a, "Jesús Gardea: producirse a sí mismo y desde sí mismo (I)”, entrevista de Agustín Ramos, El Financiero, 23 de abril, p. 69. 
, 1993b, "Jesús Gardea: producirse a sí mismo y desde sí mismo (II)", entrevista de Agustín Ramos, El Financiero, 4 de mayo, p. 67.

, 1999a, Donde el gimnasta, Aldus, México.

, 1999b, Reunión de cuentos, Fondo de Cultura Económica, México. [Contiene los libros: Los viernes de Lautaro (1979), Septiembre y los otros dias (1980), De Alba sombría (1985), Las luces del mundo (1986), Difícil de atrapar (1995)]

,2008, "La palabra es el cuento", en Lauro Zavala (ed.). Teorías del cuento III. Poéticas de la brevedad, Universidad Nacional Autónoma de México, México, pp. 213-218.

Löwy, Michael, 2018, “Teología negativa y utopía negativa Franz Kafka”, Redención y utopia. El judaismo libertario en Europa central. Un estudio de afinidad electiva, Ariadna Ediciones, Santiago, pp. 79-104.

Otto, Rudolf, 1965, Lo santo. Lo racional y lo irracional en la idea de Dios, Fernando Vela (trad.), Revista de Occidente, Madrid.

Zambrano, María, 1987, "Por qué se escribe”, Hacia un saber sobre el alma, Alianza, Madrid, pp. 31-38. 